\title{
Evidence of Finite Magneto-electric Coupling in SmFeO3 - PbTiO3 Solid Solutions
}

\section{Mehak Arora}

Guru Nanak Dev University

\section{Shubhpreet Kaur}

Guru Nanak Dev University

\section{Kanika aggarwal}

SLIET: Sant Longowal Institute of Engineering and Technology

\section{Sunil Kumar}

Guru Nanak Dev University

\section{Parambir Singh Malhi}

Guru Nanak Dev University

\section{Mandeep Singh}

Guru Nanak Dev University

Anupinder Singh ( $\sim$ anupinders@gmail.com )

Guru Nanak Dev University

\section{Research Article}

Keywords: Ferroelectrics, Solid state reaction, Multiferroics, Magneto-electric coupling

Posted Date: July 15th, 2021

DOI: https://doi.org/10.21203/rs.3.rs-703464/v1

License: (c) (i) This work is licensed under a Creative Commons Attribution 4.0 International License. Read Full License

Version of Record: A version of this preprint was published at Journal of Magnetism and Magnetic Materials on December 1st, 2021. See the published version at https://doi.org/10.1016/j.jmmm.2021.168928. 


\title{
Evidence of Finite Magneto-electric Coupling in $\mathrm{SmFeO}_{3}-\mathrm{PbTiO}_{3}$ Solid Solutions
}

\author{
Mehak Arora ${ }^{a}$, Shubhpreet Kaura, Kanika Aggarwalb, Sunil Kumara, Parambir Singh \\ Malhic, Mandeep Singha $^{\mathrm{a}}$, Anupinder Singh ${ }^{\mathrm{a}, *}$ \\ aDepartment of Physics, Guru Nanak Dev University, Amritsar 143005, Punjab, India \\ bepartment of Physics, Science Block, S.L.I.E.T, Longowal, Sangrur-148106, Punjab, \\ India
}

'Department of Chemistry, Guru Nanak Dev University, Amritsar 143005, Punjab, India

*anupinders.phy@gndu.ac.in

\begin{abstract}
:
Present work investigates the detailed multiferroic properties of $\mathrm{Pb}_{1-x} \mathrm{Sm}_{x} \mathrm{Ti}_{1-x} \mathrm{Fe}_{x} \mathrm{O}_{3}, \quad(x=0.21$, $0.22,0.23,0.24$ and 0.25$)$ synthesize through solid state reaction route. The structural, dielectric, ferroelectric and magnetic properties were measured. A sincere study is carried out to detect the magneto-electric coupling in all the samples through magneto-dielectric, magnetization after electric poling and magneto-pe response. The maximum value of coupling coefficient $(\gamma)$ and magneto-dielectric response (MDR) of sample $x=0.24$ has shown by magneto-dielectric properties and magnetization after electric poling whereas magneto-pe has shown that all the samples possess multiferroic nature.
\end{abstract}

Keywords: Ferroelectrics, Solid state reaction, Multiferroics, Magneto-electric coupling. 


\section{Introduction:}

Multifunctional materials attract great interest due to their unique functionalities which render them useful for a variety of novel applications [1-3]. Out of all these materials, magneto-electric multiferroics are being increasingly explored [4,5]. These special type of materials are essentially those which exhibit simultaneous magnetic and electric ordering [6]. The presence of partially filled d-orbitals is responsible for magnetic behavior, while the presence of empty $\mathrm{d}$ - orbitals contributes to the ferroelectric behavior of multiferroics $[7,8]$. The multifunctionality of these materials leads to their significant potential for applications such as memory devices (FeRAMs, MRAMs) [9,10], spintronics, sensors and biomedical applications [11-14]. Mixed perovskite (doping $\mathrm{d}^{\mathrm{n}}$ ion in ferroelectric material) is one of the widely used approach to synthesize high performance multiferroic materials [15]. Lead titanate (PT) is a very important ferroelectric material which can be used as a suitable base material for synthesizing mixed perovskite multiferroics. It has high Curie temperature $\left(\mathrm{T}_{\mathrm{c}} \sim 490^{\circ} \mathrm{C}\right)$, high ferroelectric and very high dielectric constant as compared to other ferroelectric materials. Due to its high dielectric and ferroelectric properties, PT based materials show extensive utility for sensors, transducers and memory device applications [6,16-19]. The magnetic behavior in PT is usually generated by substituting transition metal cations $\left(\mathrm{Mn}^{3+}, \mathrm{Fe}^{3+}, \mathrm{Ni}^{2+}, \mathrm{Co}^{2+}\right)$ at $\mathrm{Ti}^{4+}$ site [20]. However, this substitution of transition metal cations is reported to enhance leakage current [20]. It has been further established that, the substitution of rare earth ions $\left(\mathrm{R}^{3+}\right)$ at A-site of PT based materials suppress the leakage current $[21,22]$. The rare earth cations are generally substituted into ferroelectric perovskites by forming their solid solutions with rare earth orthoferrites $\left(\mathrm{RFeO}_{3}\right.$, where $\left.\mathrm{R}=\mathrm{Sm}, \mathrm{La}, \mathrm{Nd}\right)[23,24] . \mathrm{SmFeO}_{3}$ (SF) is an important rare earth ferrite having perovskite structure. Its crystal structure is 
orthorhombic and space group is Pbnm [25]. Its Neel temperature $\left(\mathrm{T}_{\mathrm{N}}\right)$ and spin reorientation temperatures are reported to be $\sim 670 \mathrm{~K}$ and $480 \mathrm{~K}$, respectively [26,27]. PT-SF solid solutions offer a potential possibility of realizing efficient multiferroic materials. Few studies have been reported on PT-SF solid solutions. Barranco et al. reported dielectric studies of $\mathrm{Pb}_{0.88} \mathrm{Sm}_{0.08} \mathrm{Ti}_{0.48} \mathrm{Mn}_{0.02} \mathrm{O}_{3}$ sample [28]. In another, they reported structural and electric behavior of $\mathrm{Pb}_{0.88} \mathrm{Sm}_{0.08} \mathrm{TiO}_{3}$ ceramic sample [29]. Increased Sm doping was found to lead to decreased tetragonality in these studies. Further, in these studies, the B- site doping was either not carried out or was substituted with Mn ions. Also, the ferroelectric and magnetic studies were not reported. Singh et al. [30] reported the multiferroic properties of $\left(\mathrm{Pb}_{0.8 \mathrm{Sm}} \mathrm{Sm}_{0.2}\right)\left(\mathrm{Ti}_{0.8 \mathrm{Fe}} \mathrm{F}_{2 .}\right) \mathrm{O}_{3}$ whereas structural and magnetic properties of $(1-x) \mathrm{Pb}\left(\mathrm{Zr}_{0} .45 \mathrm{Ti} 0.55\right)-(x) \mathrm{SmFeO}_{3}, 0.10 \leq x \leq 0.15$ have been reported by Randeep et al. [31]. From these studies, it is clear that PT-SF solid solutions have either been explored up to $x=0.20$ only. The possibility of extending the composition (beyond $x$ $>0.20)$ still exits. It further needs to established that at which value of $x$, the $(\mathrm{PT})_{1-x}-(\mathrm{SF})_{x}$ system transforms to pseudo cubic structure. Similarly, in these studies the coupling between magnetic and electric has either not been explored or only demonstrated using magneto-pe studies. Magnetodielectric studies are more often used to describe the presence of M-E coupling [32]. However, Catalan et al. [33] reported that the magneto - dielectric response (MDR) can also results from factors other than M-E coupling. Hence, the main aim of the present study is to synthesize and characterize the multiferroic properties of $\mathrm{Pb}_{1-x} \mathrm{Sm}_{x} \mathrm{Ti}_{1-x} \mathrm{Fe}_{x} \mathrm{O}_{3}(x=0.21,0.22,0.23,0.24,0.25)$ solid solutions using solid state reaction route. In view of the concerns raised by Catalan et al. [34], magneto-pe and magnetization with electric poling studies have also been carried out. 


\section{Experimental:}

Solid solutions of $\mathrm{Pb}_{1-x} \mathrm{Sm}_{x} \mathrm{Ti}_{1-x} \mathrm{Fe}_{x} \mathrm{O}_{3}(x=0.21,0.22,0.23,0.24$ and 0.25$)$ were prepared by conventional solid state reaction method. The raw materials $\mathrm{Sm}_{2} \mathrm{O}_{3}, \mathrm{PbO}, \mathrm{TiO}_{2}$ and $\mathrm{Fe}_{2} \mathrm{O}_{3}$ (from Sigma Aldrich, 99.9\% pure) were weighed in stoichiometric proportions and mixed well using mortar pestle for 2 hours. The powder was transferred to bottles containing acetone and zirconia balls and subject on milling for 24 hours. For phase formation, the mixed powders were calcined at $1000^{\circ} \mathrm{C}$ for 12 hours in high temperature furnace. Thereafter, powders were mixed with PVA binder ( $2 \mathrm{wt} \%)$ to form circular pellets of $10 \mathrm{~mm}$ diameter and $1 \mathrm{~mm}$ thickness with the help of hydraulic press. Afterwards, pellets were sintered at $1150^{\circ} \mathrm{C}$ (after optimization studies) for 2 hours in lead environment using closed crucible arrangement to reduce weight loss due to lead volatility. The X-ray Diffraction (XRD) data of these sintered samples were recorded using Shimadzu (Maxima) diffractometer in the range $20^{\circ}-80^{\circ}$ at a step size of $0.02^{\circ}$ and scan speed of $2 \%$ min using $\mathrm{Cu} \mathrm{K}_{\alpha}$ anode $(\lambda=1.5405 \AA)$. The surface morphology of all the samples was investigated using FESEM (Supra 55) from Carl Zeiss at $2 \mathrm{kX}$ magnification with InLens detector. A set up based on Archimedes principle, was used to measure the density of prepared samples. The electric and magnetic properties were measured by using automatic PE loop tracer from Marine India and Vibrating Sample Magnetometer (VSM) EZ9 from MicroSense respectively. The impedance analyzer (E4990A) from KEYSIGHT TECHNOLOGIES was used to determine the dielectric properties whereas magneto-electric studies such as magneto-dielectric, magneto-polarization and magnetization after electrical poling were made by performing polarization versus electric field measurement in the presence of magnetic field using PE loop tracer.

\section{Results and Discussions:}

\subsection{X- Ray Diffraction:}


Structural investigation of $\mathrm{Pb}_{1-x} \mathrm{Sm}_{x} \mathrm{Ti}_{1-x} \mathrm{Fe}_{x} \mathrm{O}_{3}$ samples, $(x=0.21,0.22,0.23,0.24,0.25)$ has been carried out by X-ray diffraction technique. The diffractograms of all the samples are shown in figure 1 . The sharp and intense peaks depict the crystalline behavior of all the samples. The splitting of peaks for $x=0.21-0.24$ between $44.4^{\circ}-48.0^{\circ}$ (figure 2a) and $55^{\circ}-60^{\circ}$ (figure $2 \mathrm{~b}$ ) is suggestive of the tetragonal phase of these samples. This may be because of the base material PT which possesses tetragonal structure. The figure also indicate that the tetragonal distortion decreases with $x$ and disappears for $x=0.25$. This disappearance of tetragonal splitting might be due to the fact that with increase in $x$ (Sm concentration), the crystal structure transforms into pseudo cubic at $x=0.25$. Thus, visual inspection of the XRD data in these $2 \theta$ ranges suggests tetragonal structure for $x=0.21-0.24$. The further confirmation of structural phase in these samples has been done by Rietveld refinement using Fullprof software. All the samples from $x=$ 0.21 - 0.25 have been refined using tetragonal phase having P4mm symmetry. The initial atomic co-ordinates and structural parameters of different atoms were kept same as those reported by Sunil et al. (having P4mm symmetry) [35]. Peak shape was modeled using Thompson Cox Hasting function and a sixth order polynomial was used to describe the background. Various parameters such as lattice parameters, zero shift, scale factor, refineable atomic positions and $\mathrm{B}_{\text {iso }}$ were successively refined. The refinement process was continued till the minimization of discrepancy factors. 


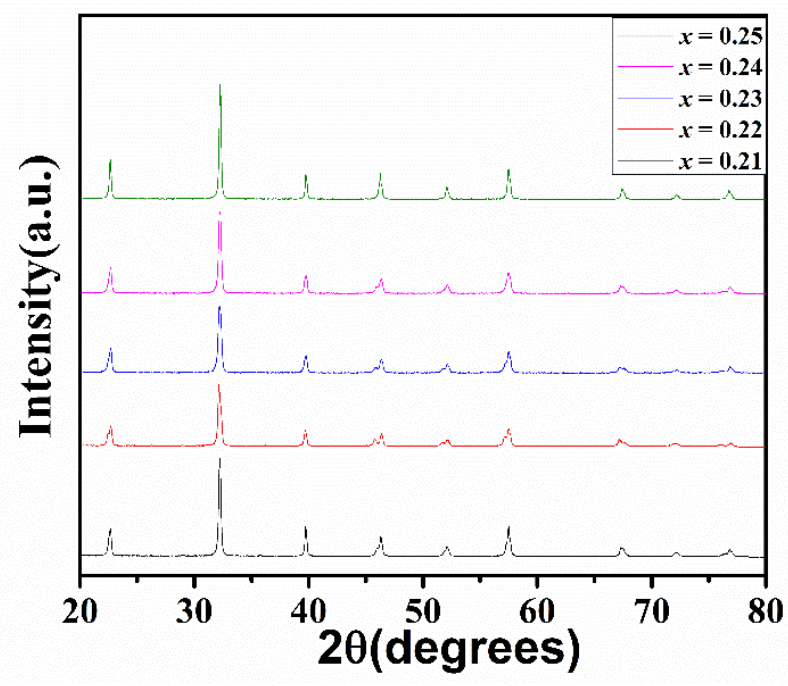

Figure 1: X-ray diffractograms of $\mathrm{Pb}_{1-x} \mathrm{Sm}_{x} \mathrm{Ti}_{1-x} \mathrm{Fe}_{x} \mathrm{O}_{3}$ for $x=0.21,0.22,0.23,0.24,0.25$ samples.
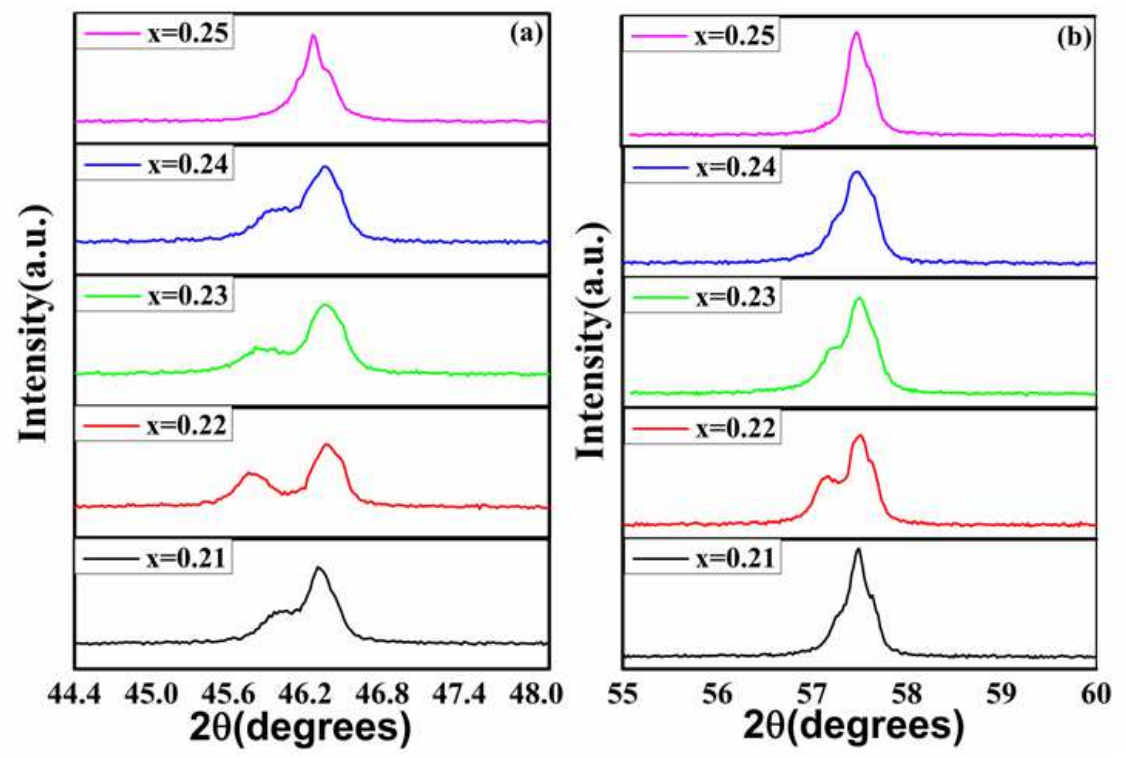

Figure 2: The splitting of peaks for $x=0.21-0.25$ in the range (a) $44.4^{\circ}-48.0^{\circ}$ and (b) $55^{\circ}-60^{\circ}$

The refined data for all the samples is shown in figure 3(a-e). The refined data shows a nice match with the experimental data. All the refined parameters are listed in table 1 . The variation of c/a ratio, lattice parameters and cell volume as a function of composition is given in figure 4(a- 
c).The figure clearly shows that a, c/a ratio and cell volume decrease non - linearly with composition $x$. This observed decrease may be due to the mismatch in the sizes of $\mathrm{Sm}^{3+}$ and $\mathrm{Pb}^{2+}$ ions [29]. The tetragonality in PT based materials is attributed to internal stresses such as compressive stress and tensile stress. Due to the smaller ionic radii of $\mathrm{Sm}^{3+}(1.08 \AA)$ and $\mathrm{Fe}^{3+}$ $(0.60 \AA)$ as compared to $\mathrm{Pb}^{2+}(1.19 \AA)$ and $\mathrm{Ti}^{4+}(0.605 \AA)$ ions, the compressive stress increases which leads to decrease in cell volume and hence results in decrease in tetragonality [36].
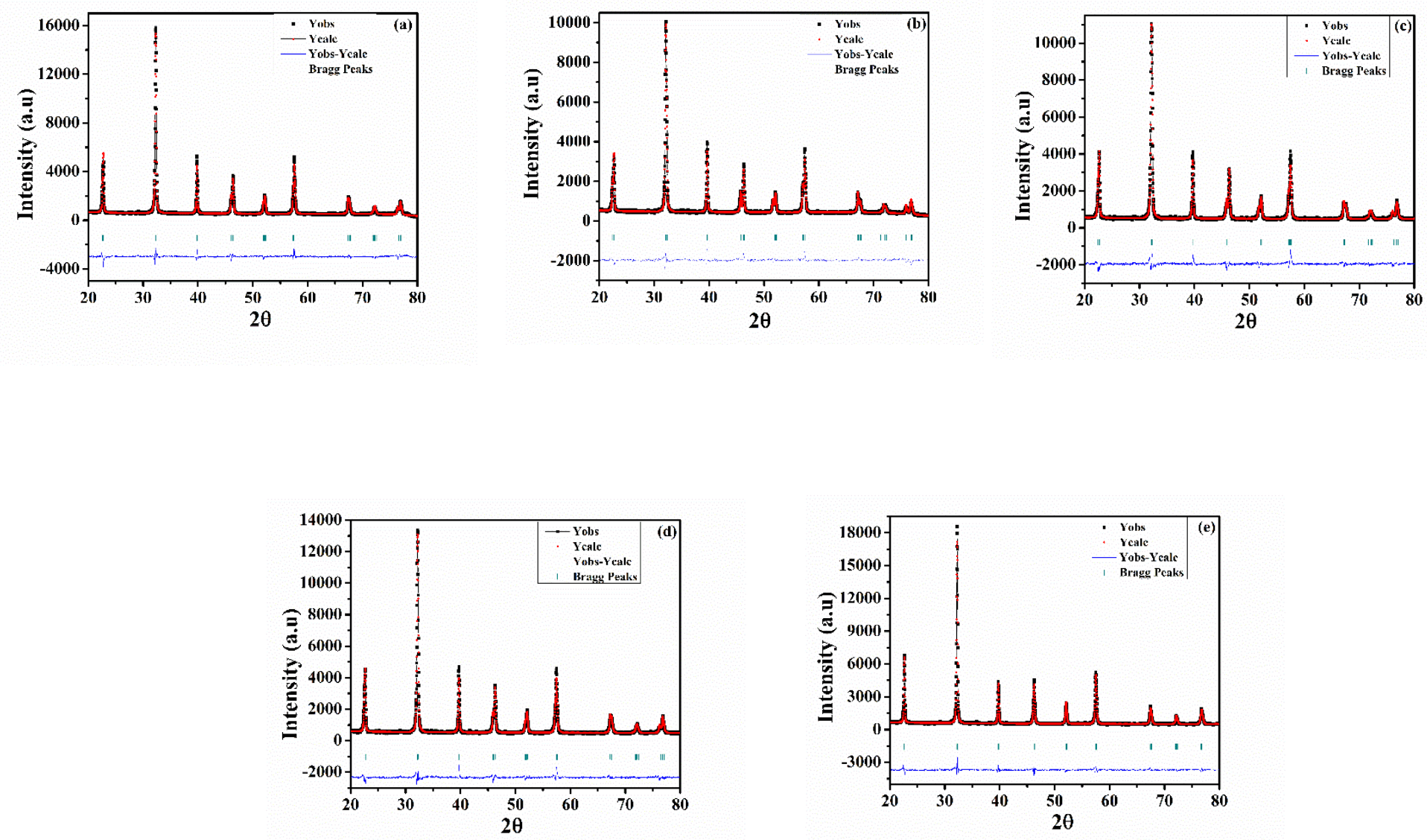

Figure 3: (a-e) represents the refined X-ray diffractograms of $\mathrm{Pb}_{1-x} \mathrm{Sm}_{x} \mathrm{Ti}_{1-x} \mathrm{Fe}_{x} \mathrm{O}_{3}$ for $x=$ $0.21-0.25$ samples respectively. 

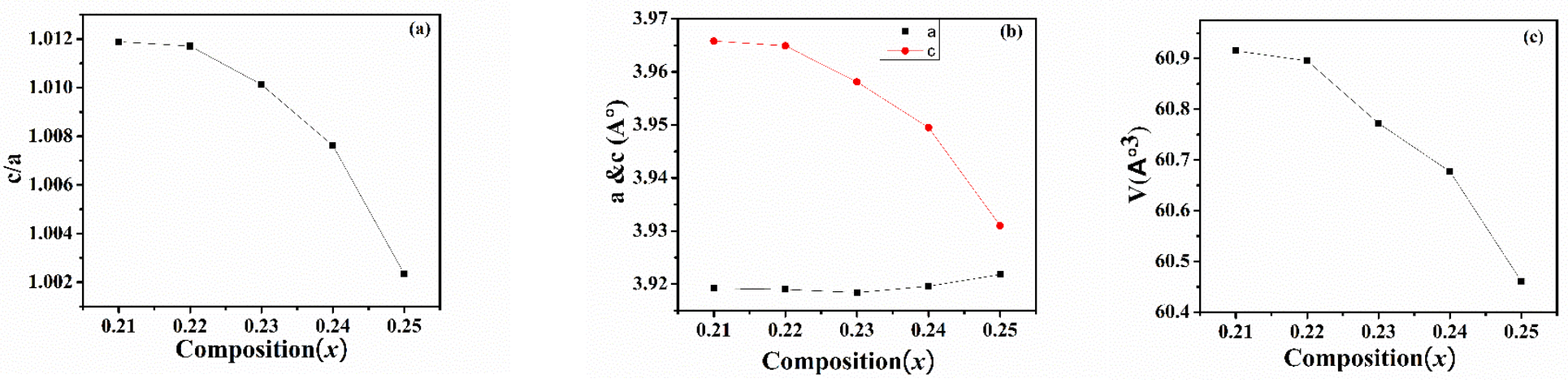

Figure 4: The variation in (a) c/a ratio, (b) lattice parameters and (c) cell volume as a function of composition.

\begin{tabular}{|c|c|c|c|c|c|}
\hline Composition & $x=0.21$ & $x=0.22$ & $x=0.23$ & $x=0.24$ & $x=0.25$ \\
\hline Space Group & $\begin{array}{c}\mathbf{P} 4 \mathrm{~mm} \\
\text { (tetragonal) }\end{array}$ & $\begin{array}{c}\text { P4mm } \\
\text { (tetragonal) }\end{array}$ & $\begin{array}{c}\mathbf{P} 4 \mathrm{~mm} \\
\text { (tetragonal) }\end{array}$ & $\begin{array}{c}\mathbf{P} 4 \mathbf{m m} \\
\text { (tetragonal) }\end{array}$ & $\begin{array}{c}\text { P4mm } \\
\text { (tetragonal) }\end{array}$ \\
\hline a (̊) & 3.9192 & 3.9190 & 3.9184 & 3.9196 & 3.9218 \\
\hline c $(\AA)$ & 3.9658 & 3.9649 & 3.9581 & 3.9495 & 3.9310 \\
\hline $\mathrm{Pb} / \mathrm{Sm}$ & $0 / 0 / 0$ & $0 / 0 / 0$ & $0 / 0 / 0$ & $0 / 0 / 0$ & $0 / 0 / 0$ \\
\hline $\mathrm{Fe} / \mathrm{Ti}$ & $0.5 / 0.5 / 0.5038$ & 0.5/0.5/0.51967 & $0.5 / 0.5 / 0.51821$ & $0.5 / 0.5 / 0.50822$ & $0.5 / 0.5 / 0.50550$ \\
\hline OI & $0.5 / 0 / 0.07350$ & $0.5 / 0.5 / 0.04380$ & $0.5 / 0.5 / 0.04064$ & $0.5 / 0.5 / 0.03907$ & $0.5 / 0.5 / 0.03892$ \\
\hline OII & $0.5 / 0 / 0.536$ & $0.5 / 0 / 0.48900$ & $0.5 / 0 / 0.54084$ & $0.5 / 0 / 0.47713$ & $0.5 / 0 / 0.51239$ \\
\hline $\mathbf{V}\left(\AA^{3}\right)$ & 60.9151 & 60.8951 & 60.77210 & 60.6772 & 60.46080 \\
\hline $\operatorname{Polarisation}\left(\mu \mathrm{C} / \mathrm{cm}^{2}\right)$ & 10.01 & 9.45 & 6.34 & 3.19 & 1.75 \\
\hline $\mathbf{R}_{\exp }$ & 7.88 & 9.08 & 8.26 & 8.09 & 7.92 \\
\hline$\chi^{2}($ GOF $)$ & 4.22 & 3.59 & 3.98 & 3.58 & 3.71 \\
\hline
\end{tabular}

Table1: Rietveld refined parameters of composition $\mathrm{Pb}_{1-x} \mathrm{Sm}_{x} \mathrm{Ti}_{1-x} \mathrm{Fe}_{x} \mathrm{O}_{3}$ for $x=0.21-0.25$ samples. 


\subsection{Morphological Studies}

The morphological studies of the prepared samples were carried out using Field emission scanning electron microscopy (FE-SEM) and the micrographs are shown in figure 5(a-e). All the images were recorded at a magnification $2 \mathrm{kX}$ using InLens detector. The well-defined and uniform grain growth in all the samples can be easily visualized. The ImageJ software was used for the determination of the grain size. The experimental density of all the samples was measured using a set up based on Archimedes Principle. The value of the obtained grain size, standard deviation, experimental density and theoretical density of all the samples is tabulated in table 2 . The table clearly shows that grain size and experimental density increase with increasing SF concentration. 

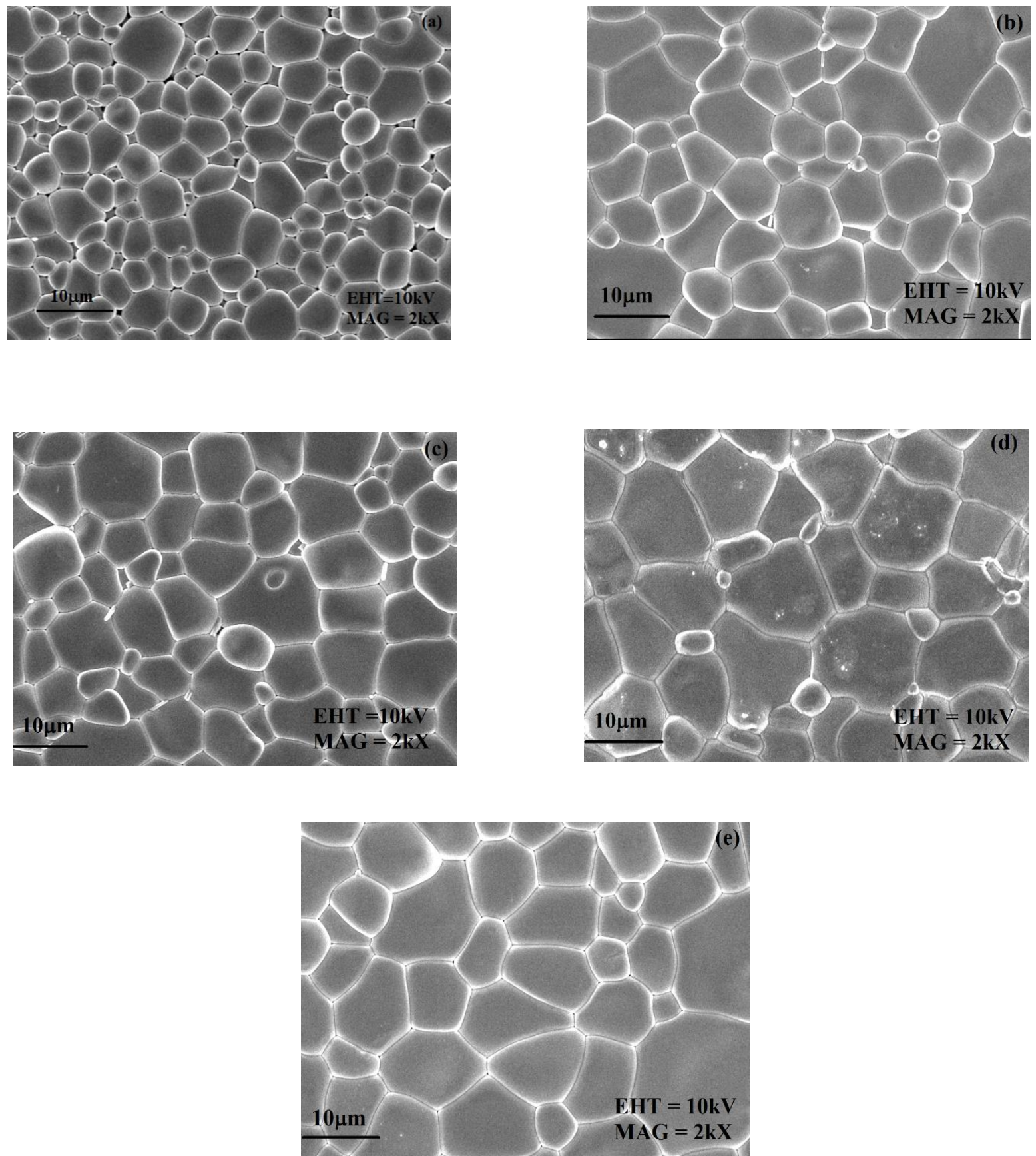

Figure 5: (a-e) shows scanning electron micrographs for composition $\mathrm{Pb}_{1-x} \mathrm{Sm}_{x} \mathrm{Ti}_{1-x} \mathrm{Fe}_{x} \mathrm{O}_{3}$ for $x=$ $0.21-0.25$ samples 


\begin{tabular}{|c|c|c|c|c|}
\hline Composition & $\begin{array}{c}\text { Grain Size } \\
(\boldsymbol{\mu m})\end{array}$ & $\begin{array}{c}\text { Standard } \\
\text { Deviation( } \boldsymbol{\sigma}) \\
\text { (length) }\end{array}$ & $\begin{array}{c}\text { Experimental } \\
\text { Density } \\
\left(\mathbf{g c m}^{-\mathbf{3}}\right)\end{array}$ & $\begin{array}{c}\text { Theoretical } \\
\text { Density } \\
\left(\mathbf{g c m}^{-\mathbf{3}}\right)\end{array}$ \\
\hline $\mathbf{x = 0 . 2 1}$ & 5.411 & 0.068 & 6.4 & 7.946 \\
\hline $\mathbf{x = 0 . 2 2}$ & 7.673 & 0.092 & 6.69 & 7.963 \\
\hline $\mathbf{x = 0 . 2 3}$ & 8.285 & 0.097 & 7.40 & 7.974 \\
\hline $\mathbf{x = 0 . 2 4}$ & 11.977 & 0.115 & 7.69 & 7.988 \\
\hline $\mathbf{x = 0 . 2 5}$ & 12.245 & 0.150 & 8.08 & 7.995 \\
\hline
\end{tabular}

Table 2: The value of the obtained grain size, standard deviation, experimental density and theoretical density of composition $\mathrm{Pb}_{1-x} \mathrm{Sm}_{x} \mathrm{Ti}_{1-x} \mathrm{Fe}_{x} \mathrm{O}_{3}$ for $x=0.21$ - 0.25 samples.

\subsection{Dielectric Properties:}

The temperature dependent dielectric constant $\left(\varepsilon^{\prime}\right)$ and dielectric loss $(\tan \delta)$ for all the samples in the range $303 \mathrm{~K} \leq \mathrm{T} \leq 823 \mathrm{~K}$ at different frequencies $(1 \mathrm{kHz} \leq \mathrm{f} \leq 100 \mathrm{kHz})$ were measured. The $\varepsilon^{\prime}$ and $\tan \delta$ versus temperature profiles of all the prepared samples are shown in figure 6(a-e) and 7(a-e) respectively. It is clear from the figure that all the samples exhibit ferroelectric transition $\left(\mathrm{T}_{\mathrm{c}}^{\mathrm{FE}}\right)$, accompanied by dielectric anomaly in the higher temperature range. Further it found that $\mathrm{T}_{\mathrm{c}}{ }^{\mathrm{FE}}$ shifts below room temperature (in $x=0.25$ sample) from $412 \mathrm{~K}$ (in $x=0.21$ sample). The $6 \mathrm{~s}^{2}$ lone pair present in $\mathrm{Pb}$ is responsible for the tetragonality in $\mathrm{PbTiO}_{3}$ by introducing 6\% strain in the lattice. Since XRD results has revealed that the doping of $\mathrm{Sm}^{3+}$ at $\mathrm{Pb}^{2+}$ reduces the c/a ratio 
and has lowered the tetragonality, the effect of lone pair of $\mathrm{Pb}$ spontaneously decreases with increase in doping. Such a change in structure from tetragonal to cubic is also reflected from phase transition profile. The decrease in $\varepsilon^{\prime}$ and $\tan \delta$ shows that the SF substitution require less thermal energy for the ferroelectric/ paraelectric phase transition [37,38]. Therefore, the $x=0.25$ sample has shown the value $\mathrm{T}_{\mathrm{c}}{ }^{\mathrm{FE}}$ below room temperature. The $\mathrm{c} / \mathrm{a}$ ratio and $\mathrm{T}_{\mathrm{c}}{ }^{\mathrm{FE}}$ have been plotted as a function of composition (x) and are shown in figure 6(f). The calculated values of the $\varepsilon^{\prime}$ and $\tan \delta$ (at $\mathrm{T}_{\mathrm{c}}{ }^{\mathrm{FE}}$ ) are mentioned in table 3. It is clear from the table that the maximum value of dielectric constant as well as $\tan \delta$ decrease with the composition $(x)$.
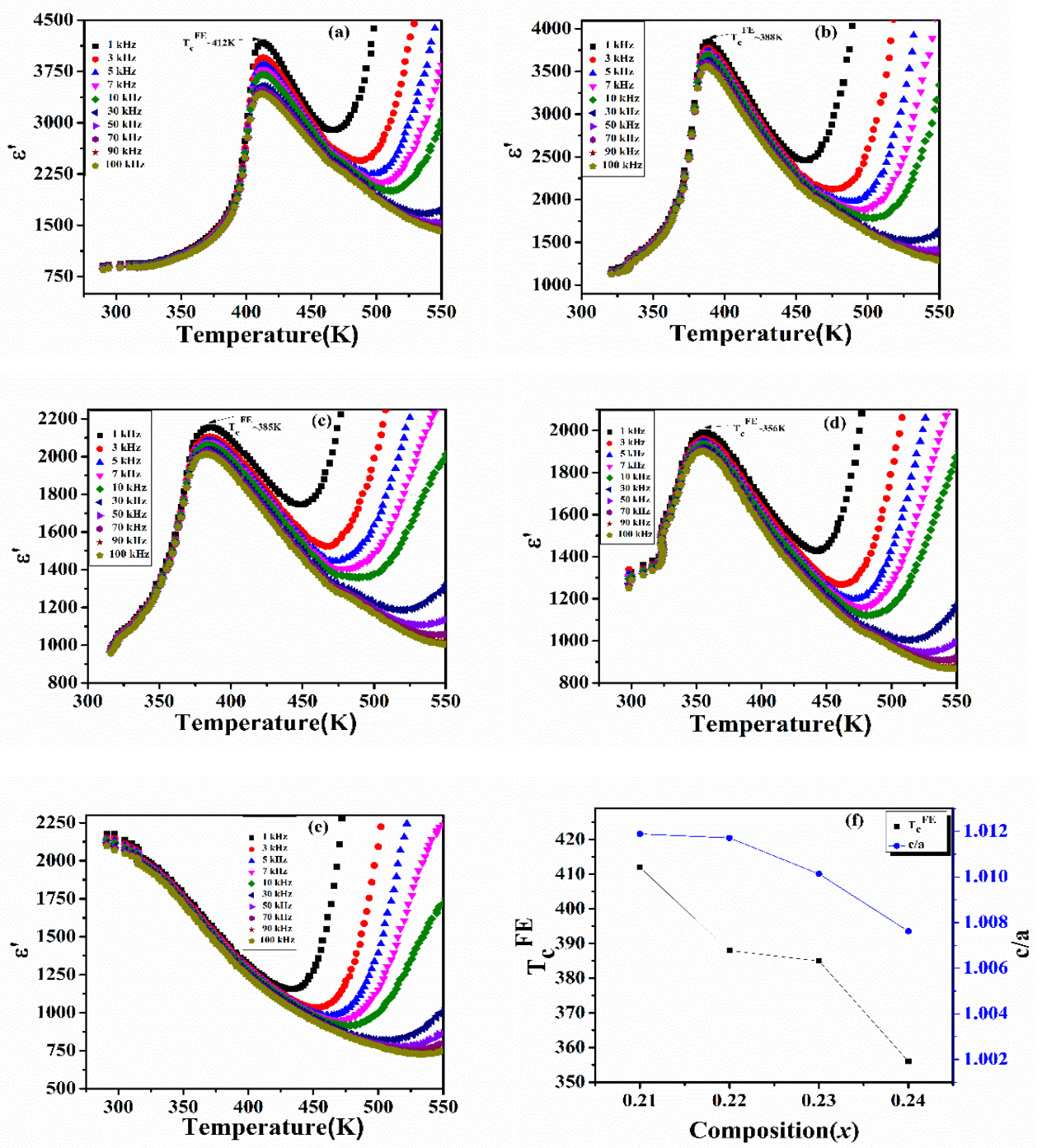
Figure 6: (a-e) gives the temperature dependent dielectric constant $\left(\varepsilon^{\prime}\right)$ of composition $\mathrm{Pb}_{1}$ ${ }_{x} \mathrm{Sm}_{x} \mathrm{Ti}_{1-x} \mathrm{Fe}_{x} \mathrm{O}_{3}$ for $x=0.21-0.25$ samples and (f) shows the variation of $\mathrm{T}_{\mathrm{c}}{ }^{\mathrm{FE}}$ and c/a ratio with $\operatorname{composition}(x)$
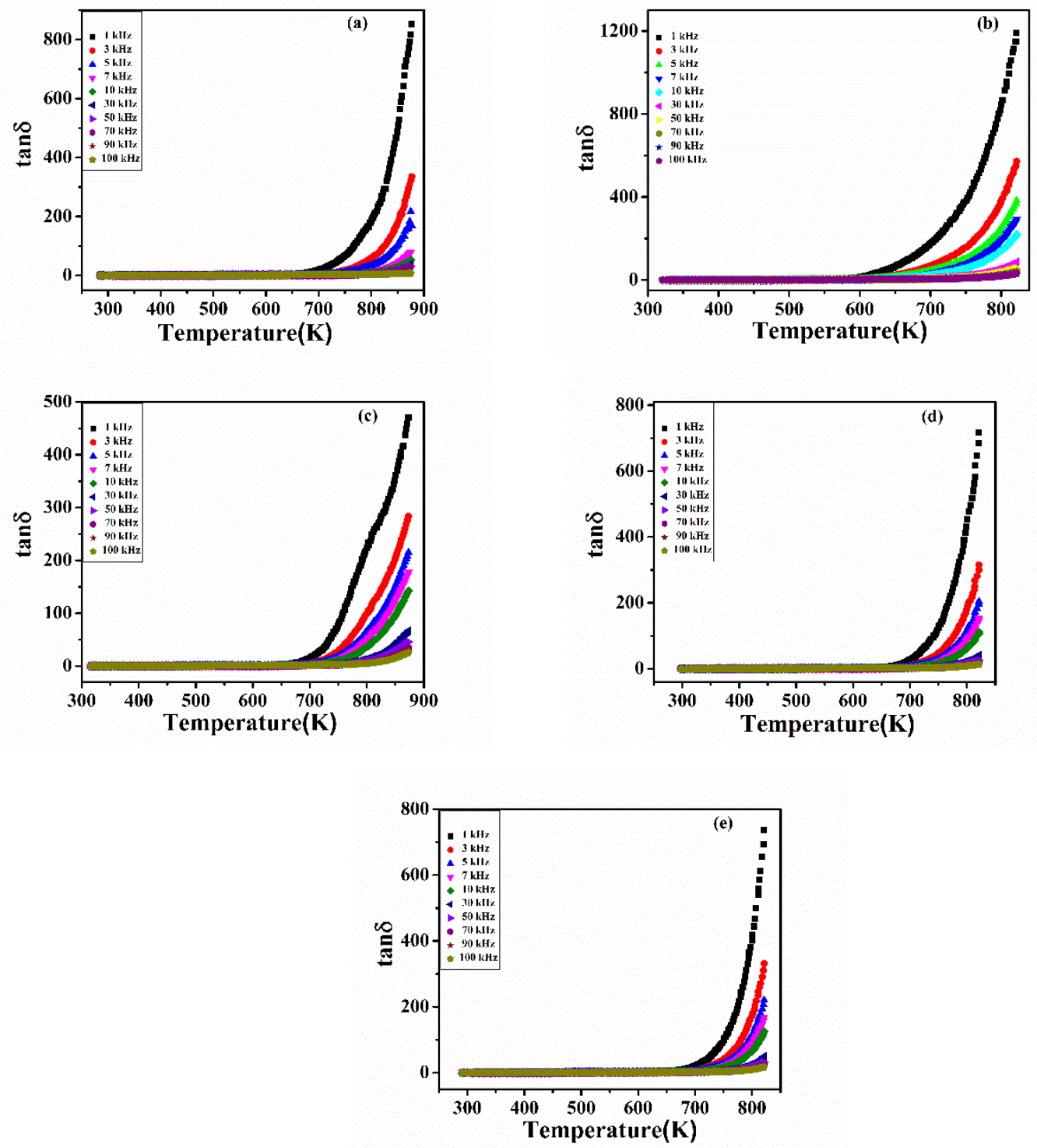

Figure 7: (a-e) gives temperature dependent tangent loss $(\tan \delta)$ of composition $\mathrm{Pb}_{1-x} \mathrm{Sm}_{x} \mathrm{Ti}_{1-}$ ${ }_{x} \mathrm{Fe}_{x} \mathrm{O}_{3}$ for $x=0.21-0.25$ samples. 


\begin{tabular}{|c|c|c|c|c|}
\hline Composition & $\mathbf{T}_{\mathrm{c}}^{\mathrm{FE}}($ in $\mathrm{K})$ & $\varepsilon^{\prime}\left(\right.$ at $\left.T_{c}{ }^{\mathrm{FE}}\right)$ & $\operatorname{Tan} \delta$ at $T_{c} \mathrm{FE}$ & $\mathbf{c} / \mathbf{a}$ \\
\hline$x=0.21$ & 412 & 3942 & 0.074 & 1.0118 \\
\hline$x=0.22$ & 388 & 3883 & 0.044 & 1.0117 \\
\hline$x=0.23$ & 385 & 2167 & 0.040 & 1.0101 \\
\hline$x=0.24$ & 356 & 2000 & 0.027 & 1.0076 \\
\hline$x=0.25$ & - & - & - & 1.0020 \\
\hline
\end{tabular}

Table 3: The values of the $\varepsilon^{\prime}$ and $\tan \delta\left(\right.$ at $\mathrm{T}_{\mathrm{c}}{ }^{\mathrm{FE}}$ ) of composition $\mathrm{Pb}_{1-x} \mathrm{Sm}_{x} \mathrm{Ti}_{1-x} \mathrm{Fe}_{x} \mathrm{O}_{3}$ for $x=0.21$ 0.25 samples.

\subsection{Ferroelectric Properties:}

The room temperature polarization versus electric field loops for all the samples $\mathrm{Pb}_{1-x} \mathrm{Sm}_{x} \mathrm{Ti}_{1-}$ ${ }_{x} \mathrm{Fe}_{x} \mathrm{O}_{3}$ (for $x=0.21-0.25$ ) were measured and given in figure 8(a-e). It can be clearly seen from the figure that loops are almost saturating for $x=0.21$ and 0.22 sample (figure $7(a, b)$ ) and increasingly non-saturated for $x=0.23$ and 0.24 (figure $7(\mathrm{c}, \mathrm{d})$ ) and it became lossy for $x=0.25$ sample (figure 7(e)). It is worth mentioning that the polarization in lead based materials is generally attributed to hybridization of titanium and oxygen ions in $3 d$ and $2 p$ states [39]. The observed shape of the loops indicate that the electric dipoles in $x=0.21$ and $x=0.22$ samples have 
an almost instantaneous (nearly ideal) response to applied ac field whereas the dipoles in $x=0.23$ and $x=0.24$ samples have a more gradual response. The observed remnant polarization $\left(\mathrm{P}_{\mathrm{r}}\right)$ for $x$ has been found to decrease from $17.42 \mu \mathrm{C} / \mathrm{cm}^{2}$ to $3.88 \mu \mathrm{C} / \mathrm{cm}^{2}$. The decreasing $\operatorname{Pr}$ values can be directly correlated with decreasing tetragonality as shown in figure 8(f).
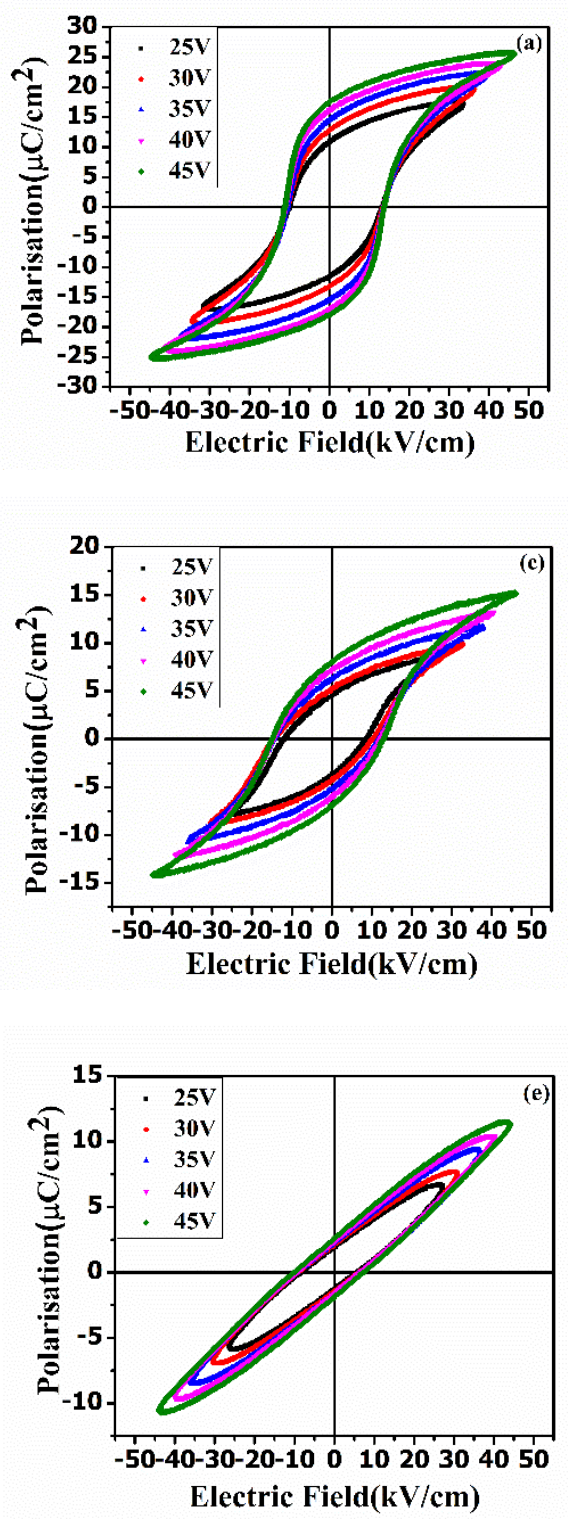
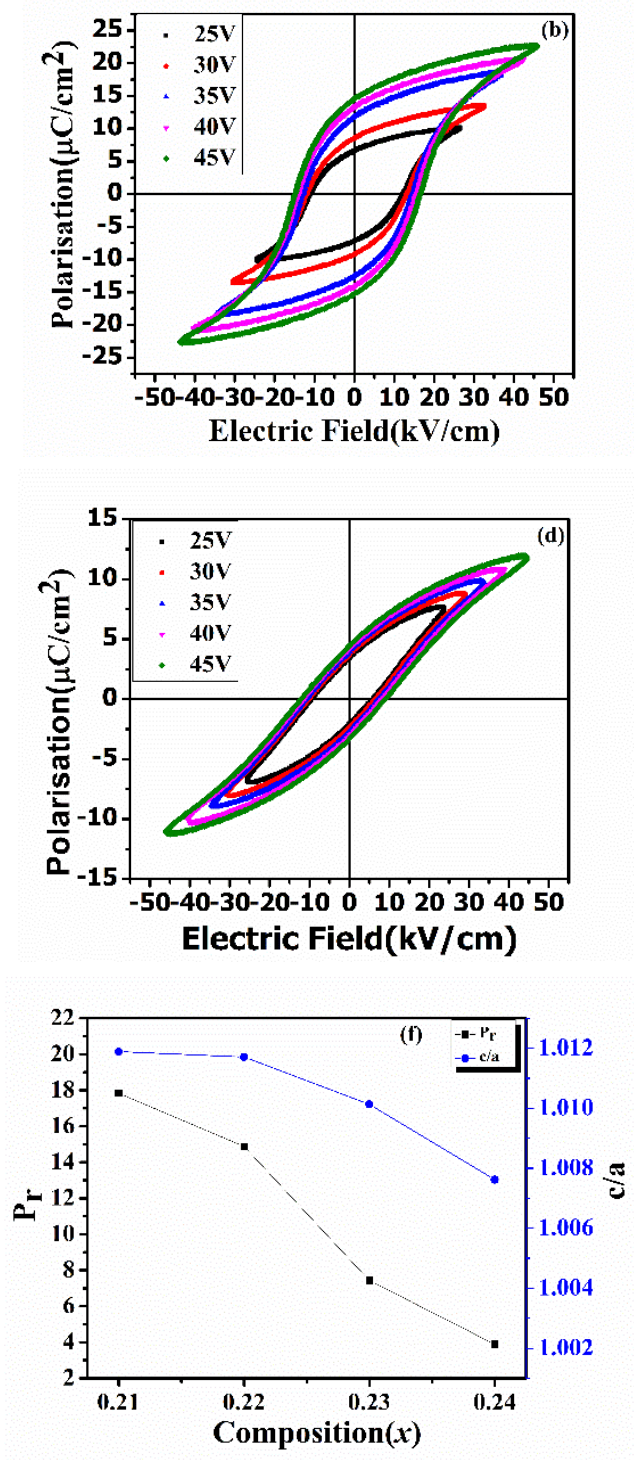
Figure 8: (a-e) shows the room temperature polarization versus electric field loops of composition $\mathrm{Pb}_{1-x} \mathrm{Sm}_{x} \mathrm{Ti}_{1-x} \mathrm{Fe}_{x} \mathrm{O}_{3}$ for $x=0.21-0.25$ samples and (f) shows the variation of $\mathrm{P}_{\mathrm{r}}$ and c/a versus composition.

\subsection{Magnetic Properties}

The room temperature magnetization (M) versus magnetic field (H) studies of $\mathrm{Pb}_{1-x} \mathrm{Sm}_{x} \mathrm{Ti}_{1-x} \mathrm{Fe}_{x} \mathrm{O}_{3}$ (for $x=0.21-0.25$ ) has been carried out and the M-H loops are shown in figure 9(a-e).The figure clearly reveals the presence of non-saturating loops with increasing remnant polarization $\left(\mathrm{M}_{\mathrm{r}}\right)$ and coercivity $\left(\mathrm{H}_{\mathrm{c}}\right)$. By the virtue of substitution of $\mathrm{Fe}^{3+}$ ion which has five unpaired electron in $\mathrm{d}$ shell, the samples attributed to magnetic order. The magnetic parameters of $x=0.21-0.25$ samples retrieved from $\mathrm{M}-\mathrm{H}$ data are given in table 4. Unlike the ferroelectric properties, the magnetic properties of these samples exhibit an increasing trend. The increase in magnetic behavior of these samples is directly correlated with increasing Fe content coming from increased SF concentration. The highest $\mathrm{M}_{\mathrm{r}}$ and $\mathrm{H}_{\mathrm{c}}$ values have been observed to be $0.341 \mathrm{emu} / \mathrm{g}$ and $1.41 \mathrm{kOe}$ in $x=0.25$ sample. However, this sample has pseudo cubic (exhibits lossy P-E loop) crystal structure.

\begin{tabular}{|c|l|}
\hline Composition & Remnant Magnetization $(\mathrm{Mr})(\mathrm{emu} / \mathrm{g})$ \\
\hline $\mathbf{x}=\mathbf{0 . 2 1}$ & 0.098 \\
\hline $\mathbf{x}=\mathbf{0 . 2 2}$ & 0.137 \\
\hline $\mathbf{x}=\mathbf{0 . 2 3}$ & 0.201 \\
\hline $\mathbf{x}=\mathbf{0 . 2 4}$ & 0.280 \\
\hline $\mathbf{x}=\mathbf{0 . 2 5}$ & 0.341 \\
\hline & \\
\hline
\end{tabular}


Table 4: The magnetic properties retrieved from $\mathrm{M}-\mathrm{H}$ data of composition $\mathrm{Pb}_{1-x} \mathrm{Sm}_{x} \mathrm{Ti}_{1-x} \mathrm{Fe}_{x} \mathrm{O}_{3}$ for $x=0.21-0.25$ samples.
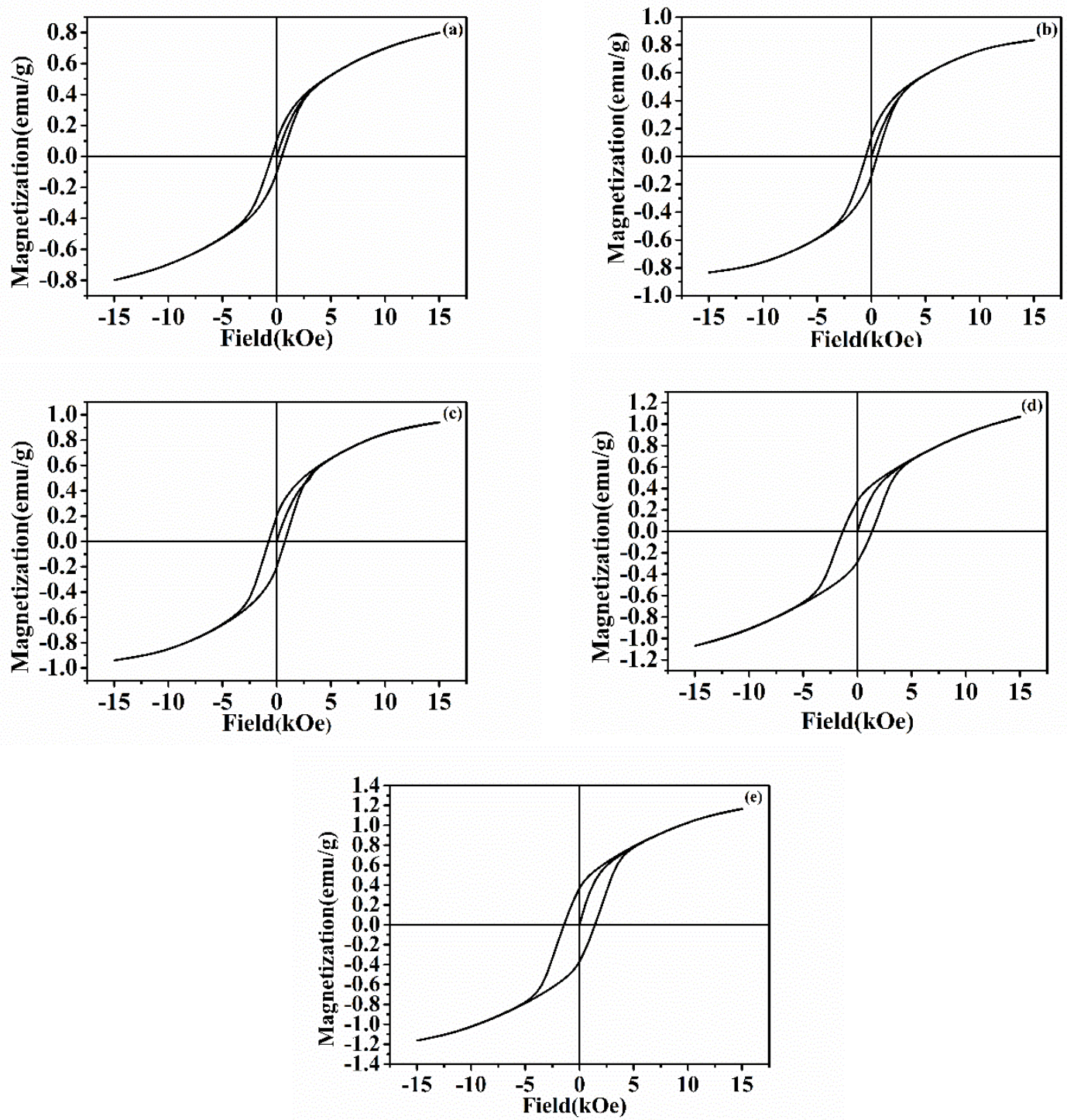

Figure 9: (a-e) shows the room temperature magnetization $(\mathrm{M})$ versus magnetic field $(\mathrm{H})$ graphs of composition $\mathrm{Pb}_{1-x} \mathrm{Sm}_{x} \mathrm{Ti}_{1-x} \mathrm{Fe}_{x} \mathrm{O}_{3}$ for $x=0.21-0.25$ samples. 


\subsection{Magneto-Electric Coupling}

The coupling between magnetic and electric components of these samples is generally reported by studying the magneto-dielectric response (MDR) of these samples. Therefore, in addition to magneto-dielectric studies we have also performed magneto-polarization (MPE) and magnetization after electrical poling.

\subsubsection{Magneto-Dielectric Properties}

The MDR of these samples was determined by performing $\varepsilon^{\prime}$ vs frequency measurements of $x=$ $0.21-0.24$ samples at $0 \mathrm{~T}, 0.5 \mathrm{~T}, 1 \mathrm{~T}, 1.5 \mathrm{~T}$ fields. The data is shown in figure $10(\mathrm{a}-\mathrm{d})$. It is clear from the data $\varepsilon^{\prime}$ decreases with increasing frequency for given magnetic field and decreases at given frequency with increasing magnetic field in all samples. The reduction of $\varepsilon^{\prime}$ with magnetic field at a given frequency is indicative of negative MDR. This decrease may be due to several factors including magneto-striction effect, magneto-resistance or magneto-electric coupling. Due to these factors, the magnetic phase $\mathrm{SmFeO}_{3}$ contracts on the application of magnetic field [40]. This shrinkage exerts the stress on the $\mathrm{PbTiO}_{3}$, the ferroelectric phase. Since, the nature of this strain is compressive, the samples thereby experience reduction in tetragonality and the off center positioning of $\mathrm{Ti}^{4+}$ ion get modified to reduce the net dipole moment of unit cell. This whole mechanism results in lowering of dielectric constant of the material after applying magnetic field [41]. The \%age change in dielectric constant with applied field is termed as magneto-dielectric response (MDR). The MDR values for all the samples were calculated using the following formula:

$$
M D R \%=\frac{\varepsilon^{\prime}(H)-\varepsilon^{\prime}(0)}{\varepsilon^{\prime}(0)} X 100 \%
$$


Here, $\varepsilon^{\prime}(\mathrm{H})$ and $\varepsilon^{\prime}(0)$ are the values of dielectric constant at applied magnetic field and in the absence of magnetic field, respectively. This results in lowering of the dielectric constant of the material [42]. It is clear that $x=0.24$ sample exhibits highest MDR\%.
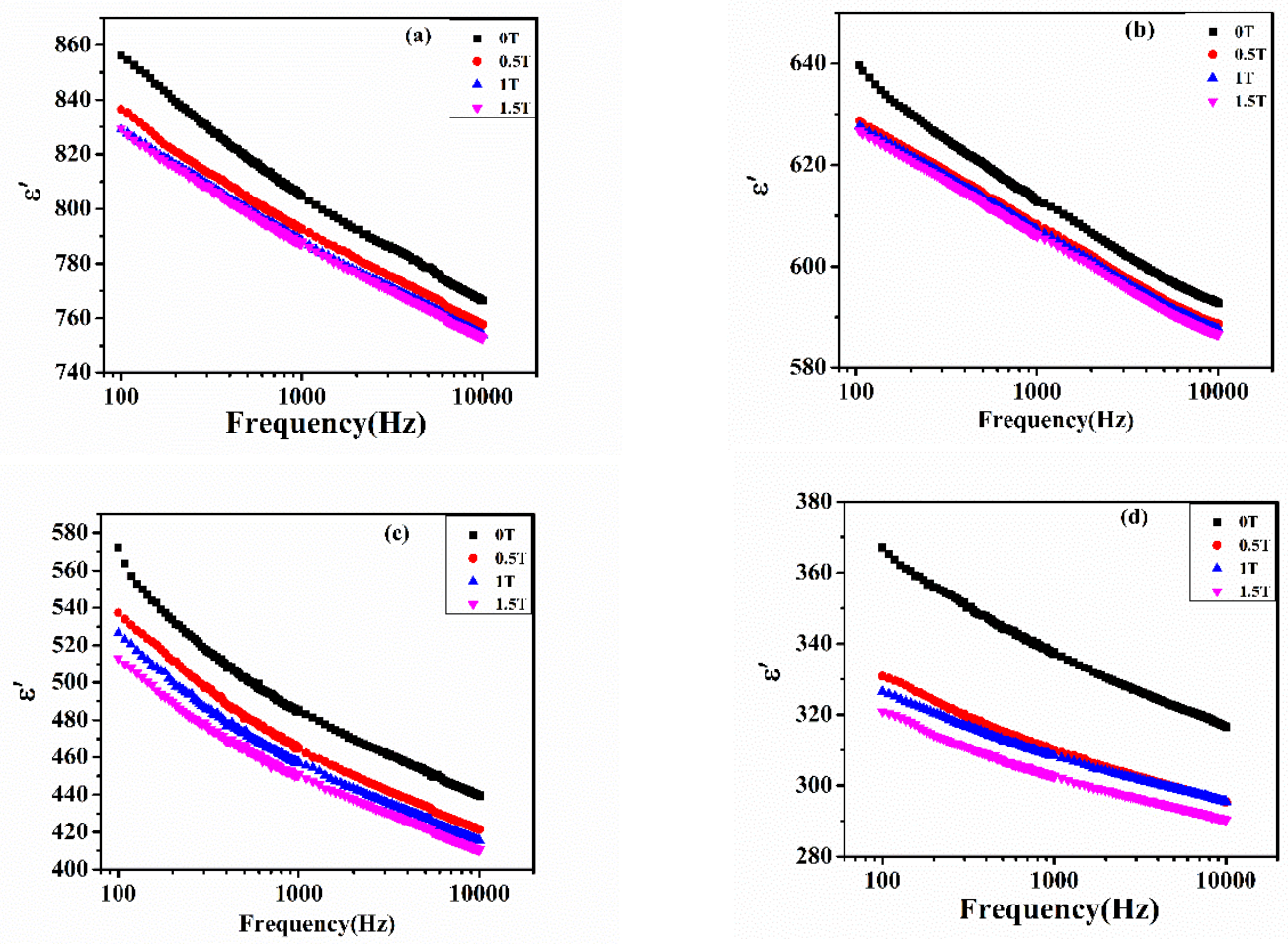

Figure 10: (a-d) shows the plots of $\varepsilon^{\prime}$ vs frequency measurements of $x=0.21-0.24$ samples at 0T, $0.5 \mathrm{~T}, 1 \mathrm{~T}, 1.5 \mathrm{~T}$ fields.

The thermodynamic potential in multiferroic system can be calculated using GinzburgLandau-Dehonshire theory [43] and expressed as:

$$
\Phi=\phi_{0}+\alpha \mathrm{P}^{2}+\frac{\beta}{2} \mathrm{P}^{4}-\mathrm{PE}+\alpha \mathrm{P}^{2}+\frac{\beta}{2} \mathrm{M}^{4}-\mathrm{MH}+\gamma \mathrm{P}^{2} \mathrm{M}^{2}
$$

where $\phi_{o}$ is reference potential, $\alpha, \alpha^{\prime}, \beta, \beta^{\prime}$ and $\gamma$ are related coupling coefficients. The $\gamma \mathrm{P}^{2} \mathrm{M}^{2}$ term arises due to coupling between electric and magnetic components of the material [44]. The magneto-electric coupling results in being proportional to $\gamma M^{2}$ as: 


$$
\frac{\varepsilon^{\prime}(H)-\varepsilon^{\prime}(0)}{\varepsilon^{\prime}(0)} \sim \gamma M^{2}
$$

Here $\mathrm{M}^{2}$ is square of magnetization and $\gamma$ is the magneto-electric coupling coefficient. The value of $\gamma$ has been calculated by linear fitting of equation (3) [44]. Since, the sample $x=0.24$ has shown the maximum MDR value. The obtained MDR values and fitted $\gamma$ values for $x=0.21,0.22$, $0.23,0.24$ have been tabulated in table 5. Therefore, the detailed investigation of MDR vs frequency profile for this sample $(x=0.24)$ only has been carried out in the range $-1.5 \mathrm{~T} \leq$ Field $\leq$ $+1.5 \mathrm{~T}$. The figure 11(a,b) represents the effect of positive and negative field on MDR values. The obtained values of MDR with varying fields at fixed frequencies $(100 \mathrm{~Hz}, 1 \mathrm{kHz}$, and $10 \mathrm{kHz})$ is shown in figure 11(c). It is clear that highest value of $\gamma$ is observed for $x=0.24$ sample. Recall that MDR \% was also maximum for this sample. The reason for the maximum value of $\gamma$ for $x=0.24$ sample could be its $\mathrm{T}_{\mathrm{c}}{ }^{\mathrm{FE}}$ being just above room temperature.

\begin{tabular}{|l|l|l|l|l|}
\hline Composition $(\boldsymbol{x})$ & $\begin{array}{l}\text { MDR(\%) at } \\
\mathbf{0 . 5 T}\end{array}$ & $\begin{array}{l}\text { MDR(\%) at } \\
\mathbf{1 T}\end{array}$ & $\begin{array}{l}\text { MDR(\%) } \\
\text { at 1.5T }\end{array}$ & $\gamma\left(\mathbf{g}^{2} / \mathrm{emu}^{2}\right)$ \\
\hline 0.21 & -2.46 & -3.28 & -3.41 & 5.6 \\
\hline 0.22 & -1.75 & -1.88 & -2.03 & 7.8 \\
\hline 0.23 & -6.10 & -7.92 & -10.33 & 8.1 \\
\hline 0.24 & -11.71 & -12.76 & -13.09 & 10.3 \\
\hline
\end{tabular}

Table 5: The obtained MDR values at different fields (0.5T, 1Tand 1.5T) and fitted $\gamma$ values of composition $\mathrm{Pb}_{1-x} \mathrm{Sm}_{x} \mathrm{Ti}_{1-x} \mathrm{Fe}_{x} \mathrm{O}_{3}$ for $x=0.21-0.24$ samples. 

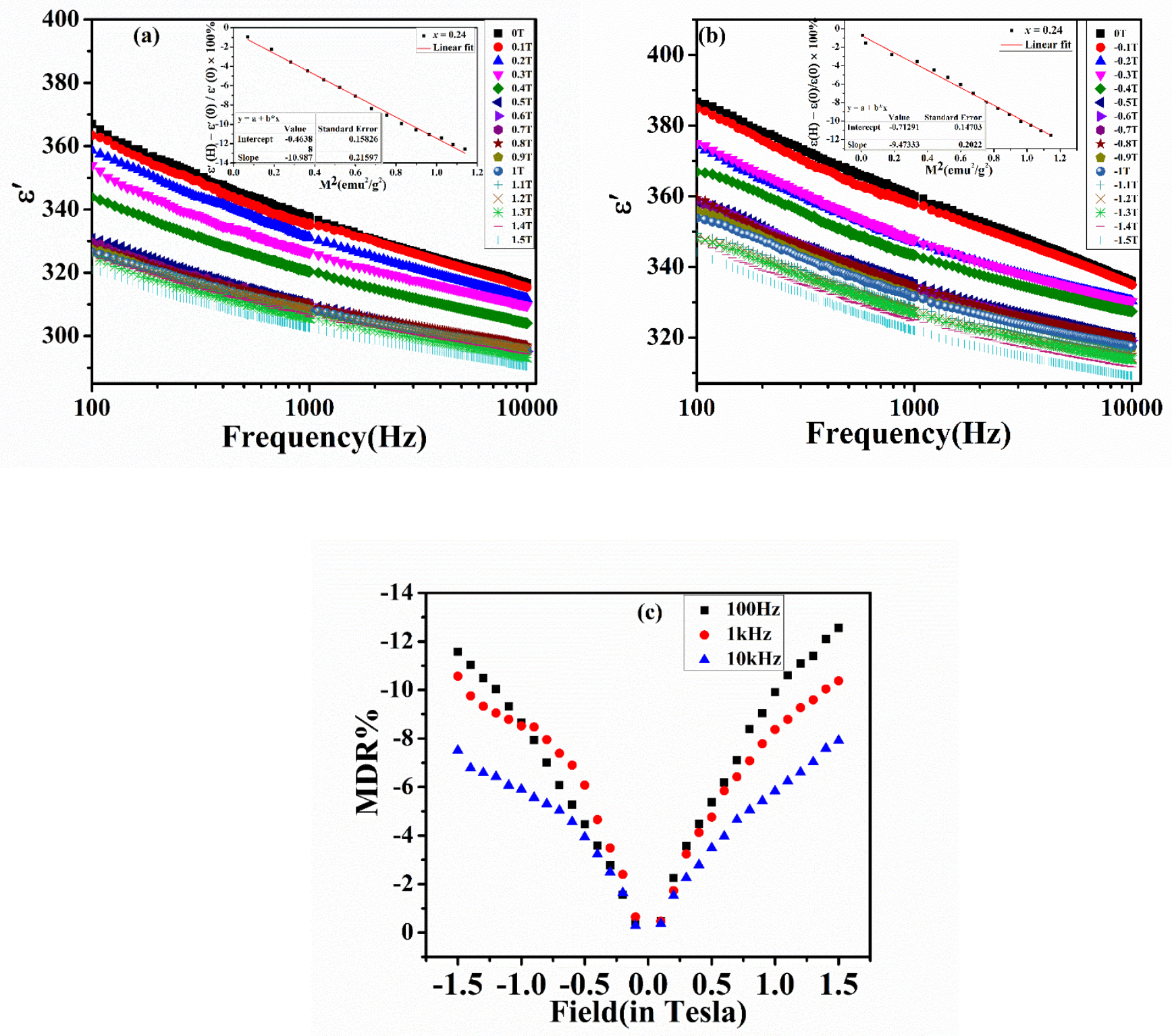

Figure 11: The plots (a) and (b) represents the effect of positive and negative field on MDR values and figure (c) represents the variation of the MDR\% with range of magnetic field (-1.5 T $\leq$ Field $\leq+1.5 \mathrm{~T})$ 


\subsubsection{Magnetic Moment}

The impact of electric field poling on the magnetic properties of $x=0.21-0.24$ samples was also investigated. In order to check whether the electric field induces any magnetization changes in these samples or not. In this regard, the pellet was broken into two pieces for each composition. One of these pieces were electrically poled at an applied voltage of $2 \mathrm{kV}$ while the other piece was kept unpoled. The first quadrant $\mathrm{M}-\mathrm{H}$ loops (Virgin Curve) of these unpoled and poled samples were measured for each composition. The typical plot for $x=0.21-0.24$ sample is shown in figure 12(a-d).
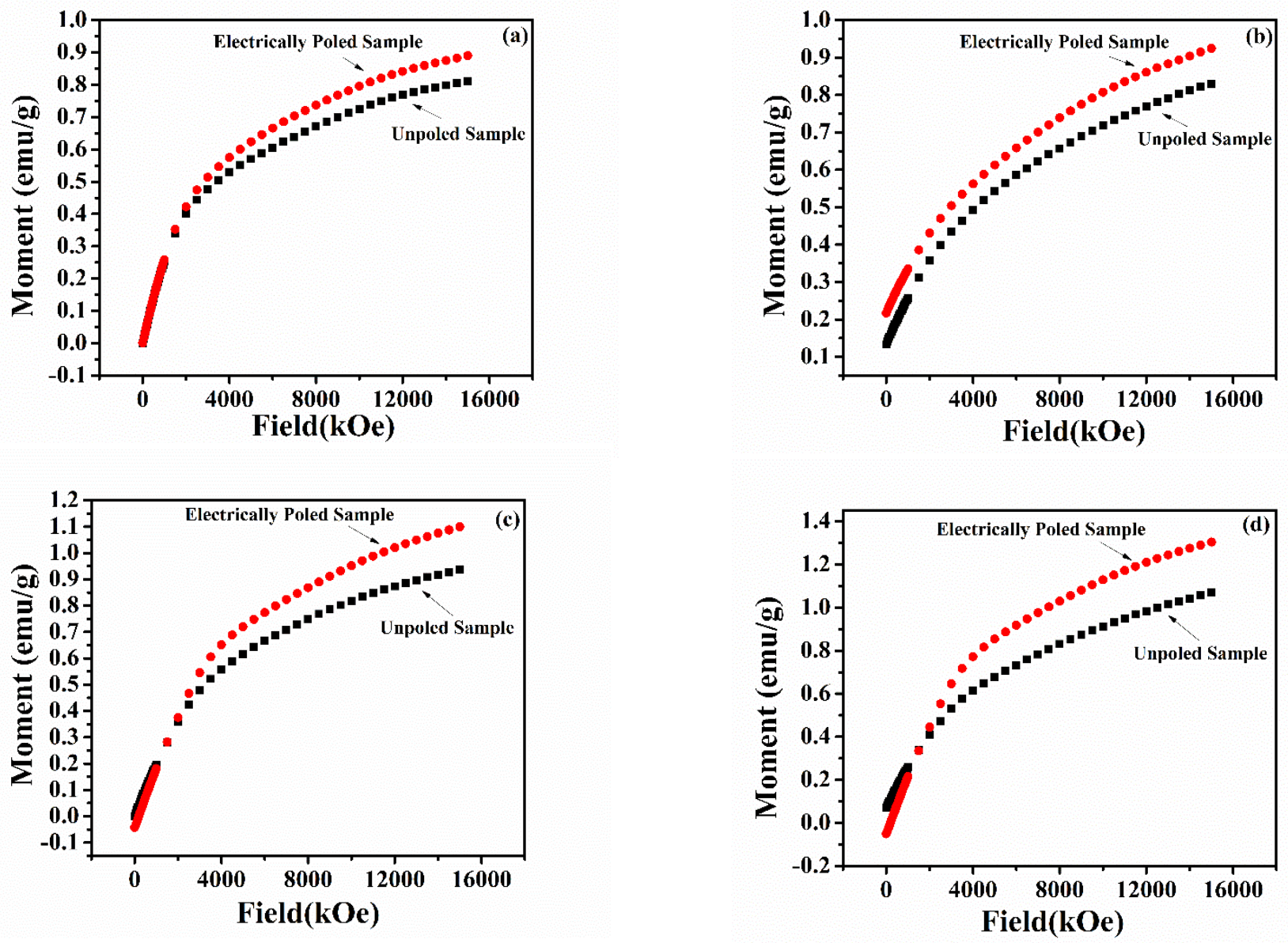
Figure 12: The first quadrant $\mathrm{M}-\mathrm{H}$ loops (Virgin Curve) of unpoled and poled samples of composition $\mathrm{Pb}_{1-x} \mathrm{Sm}_{x} \mathrm{Ti}_{1-x} \mathrm{Fe}_{x} \mathrm{O}_{3}$ for $x=0.21$ - 0.24 samples.

The plots clearly reveal that the virgin curves do not overlap and the poled samples have higher magnetization as compared to unpoled samples. Since in multiferroic materials, polarization and magnetization are coupled together. Therefore, the alignment of electric dipoles by electric poling results in enhancement in magnetization of the samples. The difference in magnetization $(\Delta \mathrm{M})$, measured at 8000 Oe for $x=0.21,0.22,0.23,0.24$ has been observed to be $0.04 \mathrm{emu} / \mathrm{g}, 0.044 \mathrm{emu} / \mathrm{g}, 0.050 \mathrm{emu} / \mathrm{g}, 0.061 \mathrm{emu} / \mathrm{g}$ respectively. Clearly, $x=0.24$ samples exhibit highest shift in magnetization. Recall that this sample also exhibited highest magnetodielectric response.

\subsubsection{Magneto-polarization}

In view of findings by Catalan et al. [33] that magneto-dielectric changes could also be the consequence of factors other than M-E coupling, we also carried magneto-pe measurements over these samples. In this regard MPE measurement over $x=0.21-0.24$ samples were carried out in 0T, 0.5T, 1T, 1.5T. The measurements for a typical ( $x=0.21-0.25$ samples $)$ are shown in figure 13(a-d). The data clearly reveals that electric polarization decreases under the influence of applied magnetic field. This is also indicative of M-E coupling in these samples. The MPE response is usually measured as:

$$
\text { MPE response }=\frac{\operatorname{Pr}(H)-\operatorname{Pr}(0)}{\operatorname{Pr}(0)} X 100 \%
$$

where $\operatorname{Pr}_{r}(H)$ and $\operatorname{P}_{r}(0)$ represent electric polarization in presence and absence of magnetic field $(\mathrm{H})$ respectively. The MPE response at $1.5 \mathrm{~T}$ of $x=0.21,0.22,0.23,0.24$ has been measured out to be $-15.46,-14.13,-9.90,-9.53$ respectively. Clearly, $x=0.21$ sample exhibits highest MPE response. 
Undoubtly, the obtained results reveal that all the samples have exhibited promising MPE response. Generally, the magnetic poling induced stress in the material which impose electric field on electric dipoles and hence variation in polarization comes into picture [45]. With this regard, the sample which has shown maximum polarization in the absence of magnetic poling exhibits more variation under magnetic field. Hence, for $x=0.21$ sample, the MPE response has attained maximum value.
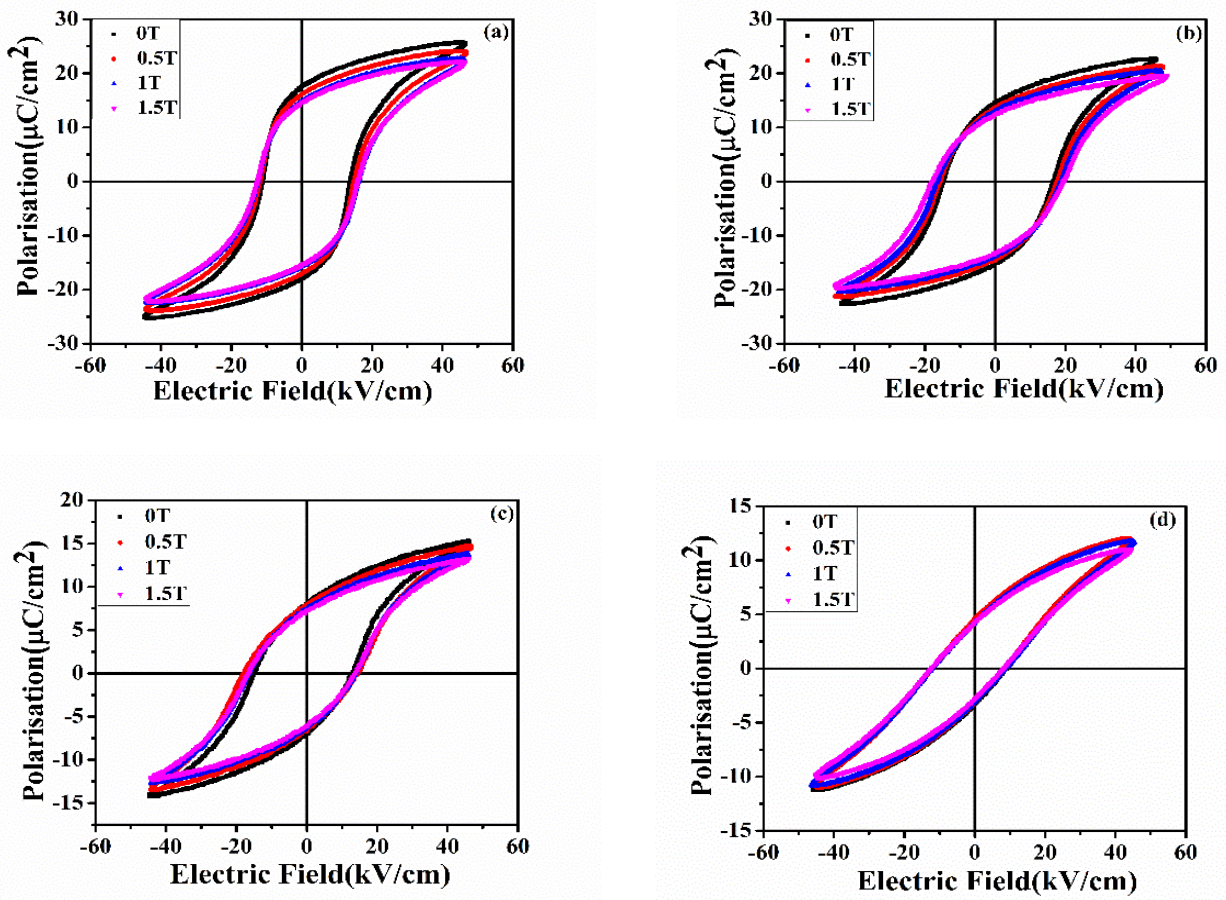

Figure 13: The variation of polarization (P) as a function of applied electric field (E) with and without magnetic field of composition $\mathrm{Pb}_{1-x} \mathrm{Sm}_{x} \mathrm{Ti}_{1-x} \mathrm{Fe}_{x} \mathrm{O}_{3}$ for $x=0.21-0.24$ samples.

\section{Conclusion:}

$\mathrm{Pb}_{1-x} \mathrm{Sm}_{x} \mathrm{Ti}_{1-x} \mathrm{Fe}_{x} \mathrm{O}_{3},(\mathrm{x}=0.21,0.22,0.23,0.24$ and 0.25$)$ have been fabricated using solid state reaction method. The tetragonal structure with $P 4 m m$ symmetry has been determined by X- Ray 
diffraction data for $x \leq 0.24$. The SEM results shows the uniform grain growth in all the samples. A good agreement with XRD data has been established by the ferroelectric transition temperature which decrease from $412 \mathrm{~K}$ to $351 \mathrm{~K}$ for $x=0.24$ (for $x=0.25, \mathrm{~T}_{\mathrm{c}}{ }^{\mathrm{FE}}<$ room temperature). The decrease in polarization and increase in magnetization has been explained through the c/a ratio and $\mathrm{Fe}^{3+}$ content respectively. The magneto-dielectric and magnetization after electric poling studies suggested that sample $x=0.24$ exhibits highest magneto-electric response.

\section{Acknowledgements}

The authors wish to thank the Centre for Emerging Life Sciences, GNDU for providing

characterization facilities (FE-SEM). Author Mehak Arora also wishes to thank Rusa-2.0 and DST-SERB for providing financial support.

\section{Conflict of interest:}

There is no conflict of interest for this manuscipt. 
[1] C.W. Nan, M.I. Bichurin, S. Dong, D. Viehland, G. Srinivasan, Multiferroic magnetoelectric composites: Historical perspective, status, and future directions, J. Appl. Phys. 103 (2008).

[2] N.A. Spaldin, S. Cheong, R. Ramesh, Multiferroics: Past, present, and future Additional resources for Physics Today, Cit. Phys. Today. 63 (2010) 38. http://www.physicstoday.org/resource/1/PHTOAD/v63/i10http://www.physicstoday.org/I nformation:http://www.physicstoday.org/about_usDailyEdition:http://www.physicstoday. org/daily_edition.

[3] M. Bibes, A. Barthélémy, Multiferroics: Towards a magnetoelectric memory, Nat. Mater. 7 (2008) 425-426.

[4] J.P. Velev, S.S. Jaswal, E.Y. Tsymbal, Multi-ferroic and magnetoelectric materials and interfaces, (2011).

[5] M. Gajek, M. Bibes, S.T. Ephane, K. Bouzehouane, B. El, J. Fontcuberta, A.G.N. Es, Tunnel junctions with multiferroic barriers, 6 (2007).

[6] G.A. Smolenskii, I.E. Chupis, Ferroelectromagnets, Sov. Phys. - Uspekhi. 25 (1982) 415448.

[7] D. Khomskii, Classifying multiferroics: Mechanisms and effects, Physics (College. Park. Md). 2 (2009).

[8] N.A. Hill, Why are there so few magnetic ferroelectrics?, J. Phys. Chem. B. 104 (2000) 6694-6709. 
[9] D. Storage, Multiferroic memories Model interfaces, 6 (2007) 256-257.

[10] J.M. Chem, Applications of magnetoelectrics, (2012) 4567-4574.

[11] C. Schmitz-Antoniak, D. Schmitz, P. Borisov, F.M.F. De Groot, S. Stienen, A. Warland, B. Krumme, R. Feyerherm, E. Dudzik, W. Kleemann, H. Wende, Electric in-plane polarization in multiferroic $\mathrm{CoFe} 2 \mathrm{O}$ 4/BaTiO3 nanocomposite tuned by magnetic fields, Nat. Commun. 4 (2013).

[12] K.C. Verma, R.K. Kotnala, N.S. Negi, Improved dielectric and ferromagnetic properties in Fe-doped PbTi O3 nanoparticles at room temperature, Appl. Phys. Lett. 92 (2008).

[13] C.M. Leung, J. Li, D. Viehland, X. Zhuang, A review on applications of magnetoelectric composites: From heterostructural uncooled magnetic sensors, energy harvesters to highly efficient power converters, J. Phys. D. Appl. Phys. 51 (2018).

[14] N.A. Spaldin, R. Ramesh, Advances in magnetoelectric multiferroics, Nat. Mater. 18 (2019) 203-212.

[15] S. Kumar, J. Pal, S. Kaur, V. Sharma, S. Dahiya, P.D. Babu, M. Singh, A. Ray, T. Maitra, A. Singh, Correlation between multiferroic properties and processing parameters in NdFeO3-PbTiO3 solid solutions, J. Alloys Compd. 764 (2018) 824-833.

[16] W. Eerenstein, N.D. Mathur, J.F. Scott, Multiferroic and magnetoelectric materials, Nature. 442 (2006) 759-765.

[17] H. Schmid, Multi-ferroic magnetoelectrics, Ferroelectrics. 162 (1994) 317-338..

[18] K. Aizu, Possible species of ferromagnetic, ferroelectric, and ferroelastic crystals, Phys. Rev. B. 2 (1970) 754-772.. 
[19] C. Zhang, M. Shang, M. Liu, T. Zhang, L. Ge, H. Yuan, S. Feng, Multiferroicity in SmFeO3 synthesized by hydrothermal method, J. Alloys Compd. 665 (2016) 152-157.

[20] A. Singh, R. Chatterjee, Magnetization induced dielectric anomaly in multiferroic $\mathrm{LaFeO} 3$ - PbTiO3 solid solution, Appl. Phys. Lett. 93 (2008) 1-4.

[21] J.E. Garcia, V. Gomis, R. Perez, A. Albareda, J.A. Eiras, Unexpected dielectric response in lead zirconate titanate ceramics: The role of ferroelectric domain wall pinning effects, Appl. Phys. Lett. 91 (2007) 1-4.

[22] H. JAFFE, Piezoelectric Ceramics, J. Am. Ceram. Soc. 41 (1958) 494-498.

[23] A. V. Kimel, A. Kirilyuk, P.A. Usachev, R. V. Pisarev, A.M. Balbashov, T. Rasing, Ultrafast non-thermal control of magnetization by instantaneous photomagnetic pulses, Nature. 435 (2005) 655-657.

[24] D. Bossini, D. Malik, B. Redlich, A.F.G. Van Der Meer, R. V. Pisarev, T. Rasing, A. V. Kimel, Time-resolved nonlinear infrared spectroscopy of samarium ions in $\mathrm{SmFeO}$, Phys. Rev. B - Condens. Matter Mater. Phys. 87 (2013) 2-5.

[25] J.H. Lee, Y.K. Jeong, J.H. Park, M.A. Oak, H.M. Jang, J.Y. Son, J.F. Scott, Spin-cantinginduced improper ferroelectricity and spontaneous magnetization reversal in $\mathrm{SmFeO}$, Phys. Rev. Lett. 107 (2011) 1-5.

[26] Y.K. Jeong, J.H. Lee, S.J. Ahn, H.M. Jang, Temperature-induced magnetization reversal and ultra-fast magnetic switch at low field in $\mathrm{SmFeO}$ 3, Solid State Commun. 152 (2012) $1112-1115$.

[27] L.G. Marshall, J.G. Cheng, J.S. Zhou, J.B. Goodenough, J.Q. Yan, D.G. Mandrus, 
Magnetic coupling between Sm3 + and the canted spin in an antiferromagnetic SmFeO 3 single crystal, Phys. Rev. B - Condens. Matter Mater. Phys. 86 (2012) 3-7.

[28] A. Peláiz-Barranco, J.D.S. Guerra, F. Calderón-Piñar, C. Aragó, O. García-Zaldívar, R. López-Noda, J.A. Gonzalo, J.A. Eiras, Dielectric response features and oxygen migration on rare earth modified lead titanate ferroelectric ceramics, J. Mater. Sci. 44 (2009) 204211.

[29] A. Peláiz-Barranco, Y. Mendéz-González, F. Calderón-Piñar, D.C. Arnold, D.J. Keeble, J.D.S. Guerra, Structural analysis and electric behavior in rare earth modified lead titanate ferroelectric ceramics, Ferroelectrics. 403 (2010) 213-218.

[30] A. Singh, I. Choudhary, S. Mehta, S. Dahiya, C. Singh, Optimal multiferroic properties and enhanced magnetoelectric coupling in $\mathrm{SmFeO} 3$ - PbTiO3 solid solutions Optimal multiferroic properties and enhanced magnetoelectric coupling in, 084106 (2010) 1-5.

[31] R. Kaur, A. Kaur, V. Sharma, A. Singh, L. Singh, M. Singh, SC, J. Alloys Compd. (2017)..

[32] S. Nandy, P.S. V Mocherla, E. Abdelhamid, B. Nadgorny, R. Naik, C. Sudakar, PHYSICAL REVIEW B 103 , 184406 ( 2021 ) Coexistence of large negative and positive magnetodielectric response in $\mathrm{Bi} 1-\mathrm{x} \mathrm{Ca}$ x Fe $1-$ y Ti y O $3-\delta$ nanoparticle ceramics, 184406 (2021) 1-8.

[33] G. Catalan, Magnetodielectric effect without multiferroic coupling, Appl. Phys. Lett. (2005) 321-325.

[34] G. Catalan, Magnetocapacitance without magnetoelectric coupling, Appl. Phys. Lett. 88 
(2006) 1-4.

[35] A.S. Sunil Kumar, Kanika Agarwal, Jaswinder Pal, Shubhpreet Kaur, Mehak Arora, Parambir singh Malhi, P.D. Babu, Mandeep Singh, Compositional driven multiferroic and magnetoelectric properties of $\mathrm{NdFeO} 3 \mathrm{PbTiO} 3$ solid solutions, J. Asian Ceram. Soc. (2020).

[36] k. Okazaki, Mechanical Behavior of ferroelectric ceramics, Am. Ceram. Soc. Bull. (1984) $1150-1157$.

[37] N. Abdelmoula, H. Chaabane, H. Khemakhem, R. Von Der Mühll, A. Simon, Relaxor or classical ferroelectric behavior in A site substituted perovskite type $\mathrm{Ba} 1-\mathrm{xSm} 0.5 \mathrm{Na}$ 0.5xTiO 3, Phys. Status Solidi Appl. Mater. Sci. 203 (2006) 987-996..

[38] D.I. Woodward, I.M. Reaney, Electron diffraction of tilted perovskites, Acta Crystallogr. Sect. B Struct. Sci. 61 (2005) 387-399.

[39] Ronald E. Cohen, Origin of ferroelectricity in perovskite oxides, Nature. 358 (1992) 136138.

[40] J. Smit, H.P.J. Wijn, Physical Properties of Ferrites, Adv. Electron. Electron Phys. 6 (1954) 69-136.

[41] D.C. shilpi Banerjee, Anindya Datta, Asim Bhaumuk, Ni0.5Zn0.5Fe2O4 composite Magneto-dielectric effect in $\mathrm{Pb}(\mathrm{Zr0}$-52Ti0.48)O3 filled nanoporou, Bull. Mater. Sci. 35 (2012) 919-924.

[42] P. Pan, J. Tao, F. Ma, N. Zhang, Magnetodielectric effect in $(1-\mathrm{x})(\mathrm{Ba} 0.88 \mathrm{Ca} 0.12)(\mathrm{Ti} 0.88 \mathrm{Zr} 0.12) \mathrm{O} 3-\mathrm{xCoFe} 2 \mathrm{O} 4$, J. Magn. Magn. Mater. 453 (2018) 
91-95.

[43] M. Singh, J. Singh, M. Kumar, S. Kumar, Investigations on multiferroic properties of lead free (1-x)BCZT-xCZFMO based particulate ceramic composites, Solid State Sci. 108 (2020) 106380.

[44] T. Kimura, S. Kawamoto, I. Yamada, M. Azuma, M. Takano, Y. Tokura, Magnetocapacitance effect in multiferroic BiMnO3, Phys. Rev. B - Condens. Matter Mater. Phys. 67 (2003) 2-5.

[45] A. Khalid, G.M. Mustafa, S. Naseem, S. Atiq, Sm-mediated dielectric characteristics and tunable magneto-electric coefficient of 0.5Bi 1-x Sm x Fe 0.95 Mn 0.05 O 3 -0.5PbTiO 3 composites, Ceram. Int. 45 (2019) 7690-7695. 


\section{Author Contribution:}

Mehak Arora: Investigation, data curation, software, conceptualization, writing original draft.

Shubhpreet Kaur: Conceptualization

Kanika Aggarwal: Reviewing

Sunil Kumar: Writing-reviewing and editing

Parambir Singh Malhi: Visualization

Mandeep Singh: Investigation, Validation

Anupinder Singh: Supervision 